\title{
Clinical and infrared pupillometry in central retinal vein occlusion
}

\author{
P A Bloom, D Papakostopoulos, Y Gogolitsyn, J A Leenderz, S Papakostopoulos, R H B Grey
}

\begin{abstract}
Measurements of pupillary reactivity and size were recorded using neutral density filters and infrared pupillometry (IRP) in a prospective masked study of acute central retinal vein occlusion (CRVO) to quantify the two methods of measurement and to compare their value in the prediction of rubeosis. Thirty two patients were examined within 45 days of disease onset. The mean relative afferent pupillary defect (RAPD) with filters was significantly greater in patients who developed rubeosis than in those who did not $(0.9$ vs $0.3 \log$ units; $p=0.012)$. Using IRP, the pupillary diameters in the dark (maximum) and in the light (minimum) were significantly greater, the rate of pupillary constriction was significantly lower, and the latency of constriction was significantly greater in affected eyes than in unaffected eyes. The differences between affected and unaffected eyes in the IRP parameters of latency, rate, maximum, and minimum pupillary diameters were significantly greater in patients who developed rubeosis than in those who did not. Discriminant analysis of the IRP parameters correctly and statistically significantly identified rubeotic patients with $83 \%$ sensitivity and 95\% specificity. An RAPD of $\geq 0.6 \mathrm{log}$ units was $83 \%$ sensitive and $70 \%$ specific in this regard. It is concluded that pupillary reactions are abnormal in many patients with acute CRVO, as measured by both pupillometric methods. The degree of these abnormalities has a relationship to the development of rubeosis, and might prove useful in planning the follow up of these patients or in deciding whether to apply panretinal photocoagulation. The neutral density filter test is readily available but subjective. IRP is more specific, objective, and suited to further development, but requires sophisticated equipment.
\end{abstract}

(BrF Ophthalmol 1993; 77: 75-80)

Bristol Eye Hospital P A Bloom

D Papakostopoulos

S Papakostopoulos

R H B Grey

Research Centre 'Brain', St Petersburg, Russia Y Gogolitsyn

Department of Anatomy, Bristol University

J A Leenderz

Correspondence to:

Philip A Bloom FRCS

FCOphth, The Western

Ophthalmic Hospital,

Marylebone Road, London

NW1 5YE.

Accepted for publication

15 September 1992 density filters has been shown to be a sensitive predictor. ${ }^{61011}$ However, this clinical test is subjective, liable to interobserver differences, and there are variations in the levels of RAPD reported to predict rubeosis. ${ }^{691011}$

Infrared pupillometry (IRP) is not subjective and may provide a more reliable measure of the RAPD. IRP has been shown to be useful in quantifying pupillary reactions in diabetes ${ }^{1314}$ and other conditions, ${ }^{15-18}$ although to our knowledge it has not been systematically performed in CRVO. It was therefore decided to investigate clinical and infrared pupillometry in a prospective, masked study of CRVO and to compare the two methods of pupillary assessment in the prediction of rubeosis following CRVO.

\section{Patients and methods}

Patients found to be suffering from acute CRVO, on presentation to the accident and emergency department of Bristol Eye Hospital, were referred to a special clinic for assessment. All patients presented within 3 weeks of noticing a visual disturbance, and underwent a detailed clinical examination in the CRVO clinic within 2 weeks of presentation. Patients then underwent infrared pupillometry within 10 days of clinical examination, and at least 7 days after instillation of any topical medication. This ensured that the effect of pupil dilatation did not influence the results.

The pupillometric investigator (DP) was not provided with clinical details except that patients being assessed had recently suffered a CRVO in one eye. Patients were followed up once a month by the same clinical investigator (PB) for at least 9 months. The pupillometric results were analysed after this period of follow up. If rubeosis iridis was noted during follow up, panretinal photocoagulation (PRP) was performed.

\section{CLINICAL EXAMINATION}

Pupil sizes were measured under room illumination. A swinging flashlight test was performed under standardised conditions, holding a Keeler neutral density filter bar in front of the unaffected eye. This rigid bar consists of a series of neutral density filters which range in density from 0 to $3.0 \log$ units (LU), in steps of $0.3 \mathrm{LU}$. The technique used was that described by Thompson. ${ }^{19}$ The balance point was reached within six swings of the light.

Slit-lamp examination, including gonioscopy, sought the early sign of rubeosis iridis - that is, rubeotic vessels at the pupil margin or in the iridocorneal angle. If rubeosis was suspected, the patient was reviewed weekly until progression of the subtle signs enabled a definite diagnosis to be made.

Fundal examination was performed after pupillary dilatation. A clinical diagnosis of 
CRVO was made by identification of the typical fundal signs of CRVO, namely dilated and tortuous retinal veins, retinal haemorrhages at the posterior pole extending towards the midperiphery in all four quadrants, and unilateral disc swelling, in association with a reduction of visual acuity.

\section{INCLUSION AND EXCLUSION CRITERIA}

Only patients with a definite diagnosis of acute CRVO, who could undergo clinical assessment and IRP within 60 days of the onset of visual symptoms, were included in the study. In practice, all patients were seen and examined within 45 days of onset. Criteria for exclusion from the study were previous significant ophthalmic disease in either eye, previous ophthalmic surgery, the use of topical or systemic medications, and previous photocoagulation.

A total of 32 patients ( 21 male, 11 female), age range 48-85 years (mean 67 (SD 9) years) were included in the study. Two other patients who were initially included, declined to undergo the tests. Patients underwent clinical assessment and RAPD measurement between 10 and 35 days from onset of CRVO (mean 24 (SD 7) days), then underwent IRP between 17 and 45 days from onset of CRVO (mean 32 (SD 8) days).

Twelve patients $(37 \cdot 5 \%)$ developed rubeosis iridis during a 9 month follow up period. The mean time from CRVO onset to rubeosis was 81 days (range 28-160 (SD 46) days). The rubeosis began at the pupil margin in nine of the 12 patients, on the trabecular meshwork alone in one patient and at both of these sites in two patients.

Table 1 Results of clinical RAPD testing for all patients $(n=32)$, ranked in order of increasing $R A P D(L U=\log$ units)

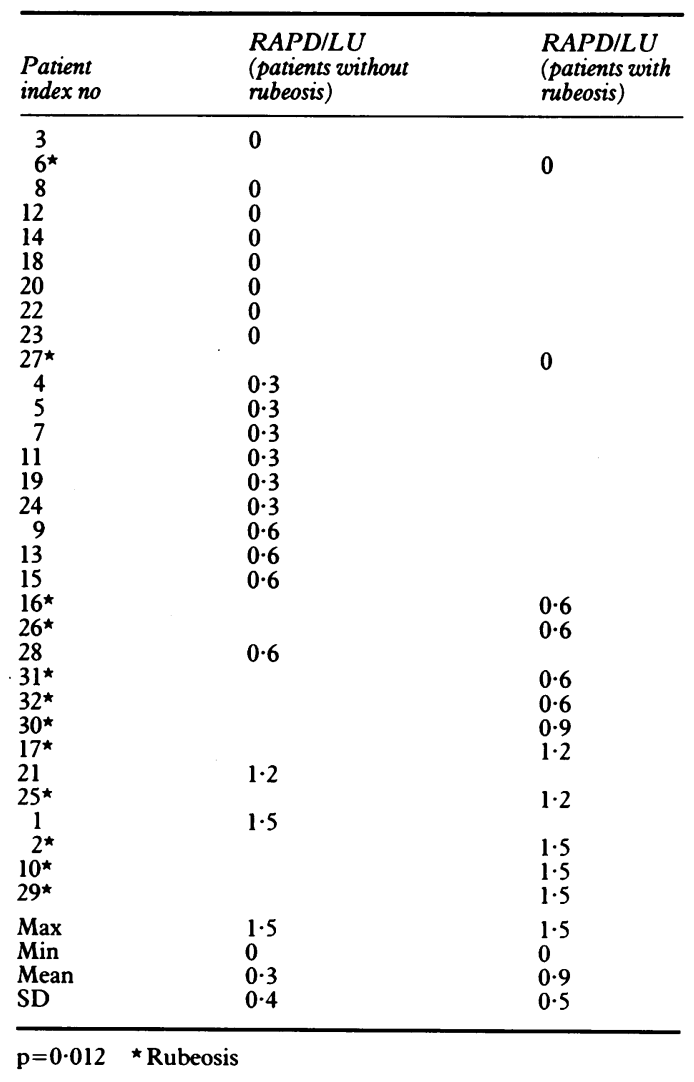

INFRARED PUPILLOMETRY

An infrared video pupillometer was used, the equipment for which has been described previously. ${ }^{20}$ In summary, it consisted of a light stimulus (optically at infinity) for each pupil and an infrared video camera for each pupil. The video cameras observed the eyes along the visual axis, via an angled mirror that reflected infrared but transmitted visible light. Subjects were darkadapted for 2 minutes and then presented with a series of exposures to a light (viewed through the angled mirror) of standardised intensity, each of 5 seconds' duration, with an inter-exposure interval of 15 seconds.

For each patient four sets of IRP responses were recorded on video for later computer analysis, corresponding to direct and consensual responses for each of the affected and unaffected pupils. For each of these four sets of recordings, computer processing of the video image derived four primary values to describe pupillary reactions. These four values were the latency of constriction ( $\mathrm{L}$, in $\mathrm{ms})$, the rate of constriction ( $R$, in $\mathrm{mm} / \mathrm{s})$, the maximum dilated pupillary diameter $(\mathrm{D}$, in $\mathrm{mm})$ before each light stimulus and the minimum constricted pupillary diameter $(\mathrm{C}$, in $\mathrm{mm})$ during each stimulus. In addition, the $\mathrm{D} / \mathrm{C}$ ratio was calculated for each set of readings.

\section{STATISTICAL ANALYSIS}

All results were analysed using paired or unpaired two-tailed $t$ tests, as appropriate, using a significance level of $5 \%$. In addition, the IRP data were subjected to the multivariate statistical techniques of discriminant analysis and multiple linear regression. ${ }^{2122}$ Discriminant analysis assesses the sensitivity and specificity of parameters in the retrospective 'prediction' of a known outcome by combining the parameters in all linear combinations. The resulting values are used to classify the subjects and to calculate the probability that the prediction is correct for each individual. In this classification, the outcome is predicted as rubeosis if the probability of rubeosis is calculated as greater than $50 \%$. A group significance level for the 'predictions' may be obtained by multiple linear regression. The outcome of rubeosis was predicted firstly using the eight primary IRP values (four parameters in each eye), and secondly using the differences in the four parameters between affected and unaffected eyes. Multiple linear regression (MLR) determined in what way the parameters could be combined to create a model (an equation) that classified (ranked) patients with rubeosis as most different from those without rubeosis. This model might then be used prospectively to predict rubeosis in new cases of CRVO, given new values for the above parameters.

\section{Results}

NEUTRAL DENSITY FILTER RESULTS

Under room illumination no patient had clinically measurable anisocoria.

In 10 patients there was no clinically measurable difference in pupillary reactions between 
Table 2 IRP results: means (standard deviations) of each parameter in affected and unaffected eyes, in patients without rubeosis $(n=20)$, patients with rubeosis $(n=12)$, and in all patients $(n=32)$ following $C R V O$

\begin{tabular}{|c|c|c|c|}
\hline Parameter & Affected eye (SD) & Unaffected eye $(S D)$ & $p$ \\
\hline $\begin{array}{l}\text { Non-rubeotic patients: } \\
\text { Latency }(\mathrm{ms}) \\
\text { Rate }(\mathrm{mm} / \mathrm{s}) \\
\text { Max diameter }(\mathrm{D})(\mathrm{mm}) \\
\text { Min diameter }(\mathrm{C})(\mathrm{mm}) \\
\text { D/C ratio }\end{array}$ & $\begin{array}{l}286(27) \\
3.9(1 \cdot 1) \\
4 \cdot 8(1 \cdot 0) \\
3.2(0.6) \\
1.5(0 \cdot 1)\end{array}$ & $\begin{array}{l}271(20) \\
4.3(0.8) \\
4.8(0.9) \\
2.9(0.7) \\
1.7(0.1)\end{array}$ & $\begin{array}{c}<0.0001 \\
0.0004 \\
0.52 \\
0.0001 \\
<0.0001\end{array}$ \\
\hline $\begin{array}{l}\text { Rubeotic patients: } \\
\text { Latency }(\mathrm{ms}) \\
\text { Rate }(\mathrm{mm} / \mathrm{s}) \\
\text { Max diameter (D) (mm) } \\
\text { Min diameter (C) (mm) } \\
\text { D/C ratio (D) }\end{array}$ & $\begin{array}{l}303(39) \\
3.2(1.4) \\
4.9(0.9) \\
3.5(0.7) \\
1.4(0.1)\end{array}$ & $\begin{array}{l}272(24) \\
4.2(0.9) \\
4.6(0.9) \\
2.7(0.6) \\
1.7(0.2)\end{array}$ & $\begin{array}{r}0.0001 \\
0.0001 \\
0.0006 \\
<0.0001 \\
0.0002\end{array}$ \\
\hline $\begin{array}{l}\text { All patients: } \\
\text { Latency }(\mathrm{ms}) \\
\text { Rate }(\mathrm{mm} / \mathrm{s}) \\
\text { Max diameter (D) (mm) } \\
\text { Min diameter }(\mathrm{C})(\mathrm{mm}) \\
\text { D/C ratio }\end{array}$ & $\begin{array}{r}292(32) \\
3.7(1.2) \\
4.9(0.9) \\
3.3(0.6) \\
1.5(0.1)\end{array}$ & $\begin{array}{l}271(21) \\
4.3(0.9) \\
4.7(0.9) \\
2.8(0.6) \\
1.7(0.2)\end{array}$ & $\begin{array}{c}<0.0001 \\
<0.0001 \\
0.006 \\
<0.0001 \\
<0.0001\end{array}$ \\
\hline
\end{tabular}

affected and unaffected eyes. In the remaining 22 patients there was an RAPD in the affected eye, ranging from $0.3-1.5 \mathrm{LU}$. The results of RAPD testing are shown in Table 1.

When present, the RAPD ranged from $0 \cdot 3-$ $1.5 \mathrm{LU}$ in patients without rubeosis and from $0.6-1.5 \mathrm{LU}$ in those with rubeosis. The mean RAPD of all patients who did not develop rubeosis was $0.3 \mathrm{LU}$, whereas that of all patients who did develop rubeosis was $0.9 \mathrm{LU}$. This difference is statistically significant $(p=0.012)$. Of the 10 patients who had no measurable RAPD, two developed rubeosis (Table 1).

\section{IRP RESULTS}

When all patients were taken as a group, IRP demonstrated slight but significant anisocoria in the light and to a lesser extent in the dark; the dilated (D) and constricted pupil diameters $(C)$ in affected eyes were significantly greater than in unaffected eyes (Table 2, bottom). The $\mathrm{D} / \mathrm{C}$ ratio was significantly smaller in affected eyes than in unaffected eyes because the effect on the constricted diameter was greater than that on the dilated diameter.

With IRP the latency of pupillary constriction in the group of affected eyes was greater, and the rate of constriction less, than that in unaffected eyes. The differences in all IRP parameters between affected and unaffected eyes are statistically significant (Table 2, bottom).

Further to these differences in the whole group, there were differences between affected and unaffected eyes in the subgroups of patients with and without rubeosis (Table 2, middle and

Table 3 IRP results: means (standard deviations) for the interocular differences (affected unaffected) in each parameter, in patients without rubeosis $(n=20)$, and with rubeosis $(n=12)$ following CRVO

\begin{tabular}{|c|c|c|c|}
\hline Parameter & $\begin{array}{l}\text { Patients without } \\
\text { rubeosis }(S D)\end{array}$ & $\begin{array}{l}\text { Patients with } \\
\text { rubeosis }(S D)\end{array}$ & $p$ \\
\hline \multicolumn{4}{|c|}{$\begin{array}{l}\text { Differences between affected and } \\
\text { unaffected eyes: }\end{array}$} \\
\hline Latency (ms) & $15(12)$ & $31(19)$ & 0.015 \\
\hline Rate $(\mathrm{mm} / \mathrm{s})$ & $-0.4(0.5)$ & $-1.0(0 \cdot 6)$ & 0.015 \\
\hline Max diameter (D) (mm) & $0(0 \cdot 2)$ & $0.3(0 \cdot 2)$ & 0.003 \\
\hline Min diameter (C) (mm) & $0.3(0 \cdot 3)$ & $0.8(0.4)$ & 0.004 \\
\hline $\mathrm{D} / \mathrm{C}$ ratio & $-0 \cdot 2(0 \cdot 1)$ & $-0.3(0 \cdot 2)$ & 0.041 \\
\hline
\end{tabular}

top). The differences in constricted pupil diameter, $\mathrm{D} / \mathrm{C}$ ratio, latency, and rate between affected and unaffected eyes are statistically significant for patients with and without rubeosis. For patients with rubeosis, the difference between the dilated pupil diameter in the affected and unaffected eyes was statistically significant but for patients without rubeosis, this difference was not statistically significant. Table 2 summarises the values for IRP parameters in affected and unaffected eyes, including the subgroups of patients with and without rubeosis, and gives significance values for the group comparisons.

Besides the differences between groups of affected and unaffected eyes, there were differences within these groups that differentiated between patients with and without rubeosis. The interocular differences in IRP parameters were all significantly greater in patients with rubeosis than in patients without rubeosis. These differences, and the significance values for the group comparisons, are summarised in Table 3. There were some differences in the absolute values of IRP parameters in affected eyes between patients with and without rubeosis (Table 2), but these differences did not achieve statistical significance.

To investigate whether the above IRP differences were due to factors in the afferent or the efferent side of the pupil reflex arc, the IRP group results from stimulated pupils (direct responses) were compared with those from unstimulated pupils (consensual responses). There were no significant differences between direct and consensual pupillary responses on stimulation of either the affected or the unaffected eye. The IRP results quoted above are the reactions of the unaffected eyes that correspond to stimulation of either eye - that is, the direct pupillary response on stimulation of the unaffected eye and the consensual response of the same (unaffected) pupil on stimulation of the affected eye.

\section{RANKING}

To investigate whether differences in the values of individual parameters enabled differentiation between patients with and without rubeosis, these values were 'ranked' - that is, listed in increasing order of magnitude. The results of this ranking are shown for RAPD in Table 1. For IRP results, patients were ranked according to the interocular difference in each individual IRP parameter.

Ranking demonstrated that rubeotic patients were clustered at one end of the table, both for RAPD and for the interocular difference in IRP parameters. The cut off between rubeotic and non-rubeotic patients using ranking, however, was not sharp and some rubeotic and nonrubeotic patients were ranked at the opposite end of the table from the majority of their fellows. Figure 1 shows the value of the interocular difference in dilated pupillary diameters plotted against the interocular difference in constricted pupillary diameters, and illustrates the overlap between rubeotic and non-rubeotic patients. The other parameters showed similar results. 


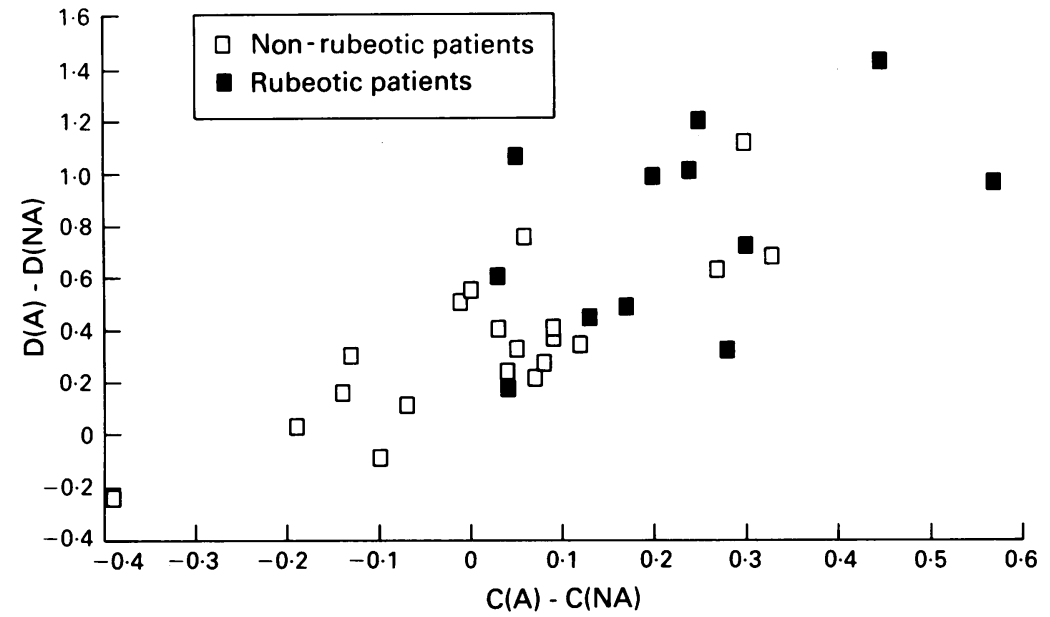

Figure 1 Graph showing the interocular difference in dilated pupil diameter $(D)$, plotted against the interocular difference in constricted pupil diameter (C).The rubeotic patients are clustered to the right of the graph, but there is some overlap with non-rubeotic patients. ( $A=$ affected eye $N A=$ unaffected eye.) ischaemic cases, complications may be reduced by panretinal photocoagulation. ${ }^{1+}$ Despite attempts to predict rubeosis following CRVO using a variety of clinical, angiographic, and electrodiagnostic parameters, ${ }^{5-12}$ no method of prediction has gained wide acceptance in clinical practice. The RAPD is a sensitive clinical method of prediction ${ }^{6} 1011$ but it is subjective and so liable to interobserver differences. An objective test of pupillary reactivity might eliminate such problems in the prediction of rubeosis.

The results of this study show that small but significant differences in pupil diameter between affected and unaffected eyes can be measured using IRP. These differences were too small to be clinically discernible.

On performing the swinging flashlight test, 22 of 32 patients had a measurable RAPD; this RAPD was significantly greater in patients who went on to develop rubeosis than in those who did not. However, two patients who developed rubeosis had no RAPD on presentation (patients 6 and 27) and two patients who did not develop rubeosis had dense RAPDs (patients 1 and 21).

The level of RAPD that has been proposed to identify those patients with sufficient ischaemia to produce rubeosis, has varied in previous reports from $0.7 \mathrm{LU}^{6}$ to $1.8 \mathrm{LU}$. ${ }^{11}$ If the level of $0.7 \mathrm{LU}$ had been used on our results (that is, $\geq 0.9 \mathrm{LU}$, because the filter bar is graded in 0.3 LU steps), six of 12 cases of rubeosis would have been correctly predicted but six of 12 would have been missed. Conversely 18 of 20 non-rubeotic cases would have been correctly predicted. In other words an RAPD of $\geq 0.9 \mathrm{LU}$ would have been $50 \%$ sensitive and $90 \%$ specific in the identification of rubeosis. If an RAPD cut off of $\geq 0.6 \mathrm{LU}$ had been used to predict rubeosis, it would also have correctly identified 24 of 32 outcomes. Ten of 12 patients with rubeosis and 14 of 20 patients without rubeosis would have been correctly identified, a sensitivity of $83 \%$ and a specificity of $70 \%$.

In addition to the different RAPD thresholds that have been used to predict rubeosis, the sensitivity and specificity of the different levels have been reported to vary. ${ }^{691011}$ This variation in the 'break point' of the RAPD probably reflects the subjectivity of the clinical test and this impugns the reliability of comparisons between

\section{Discussion}

The more ischaemic is a CRVO, the greater the incidence of rubeosis ${ }^{10}$ and of neovascular glaucoma. ${ }^{23}$ Following the early identification of

Table 4 Summary of results of discriminant analysis using IRP data. The percentage probablility of each predicted outcome $(P r)$ is given alongside the patient index number for incorrect predictions. The regression equation that calculates this probability is also shown, with the level of significance for the prediction.

\begin{tabular}{|c|c|c|c|c|c|c|}
\hline Predictor(s) & $\begin{array}{l}\text { Total } \\
\text { correct } \\
(n=32)\end{array}$ & & $\begin{array}{l}\text { Correct } \\
\text { prediction }\end{array}$ & $\begin{array}{l}\text { Incorrect } \\
\text { prediction }\end{array}$ & $\begin{array}{l}\text { Patient } \\
\text { index } \\
\text { number }\end{array}$ & $\begin{array}{l}\text { Predicted } \\
\text { probability } \\
(\%)(P r)\end{array}$ \\
\hline $\begin{array}{l}\text { (a) Latency (A) } \\
\text { (b) Latency (NA) } \\
\text { (c) Rate (A) } \\
\text { (d) Rate (NA) } \\
\text { (e) Max diameter (A) } \\
\text { (f) Max diameter (NA) } \\
\text { (g) Min diameter (A) } \\
\text { (h) Min diameter (NA) }\end{array}$ & 29 & Non-rubeotic & 10 & $2(83 \%$ sensitive $)$ & $\begin{array}{l}17 \\
27\end{array}$ & $\begin{array}{l}76 \\
87\end{array}$ \\
\hline \multicolumn{7}{|c|}{ Regression equation: $\operatorname{Pr}=0.11+0.017 \mathrm{a}-0.02 \mathrm{~b}-0.069 \mathrm{c}+0.265 \mathrm{~d}+1.19 \mathrm{e}-1.54 \mathrm{f}-0.014 \mathrm{~g}+0.543 \mathrm{~h}(\mathrm{p}=0.032)$} \\
\hline \multirow{2}{*}{$\begin{array}{l}\text { (k) Latency difference (A-NA) } \\
\text { (1) Rate difference (A-NA) } \\
\text { (m) Max diameter difference (A-NA) }\end{array}$} & \multirow[t]{2}{*}{27} & Rubeotic & 10 & $2(83 \%$ sensitive $)$ & 17 & 61 \\
\hline & & Non-rubeotic & 17 & $3(85 \%$ specific $)$ & $\begin{array}{l}11 \\
13 \\
21\end{array}$ & $\begin{array}{l}78 \\
51 \\
52\end{array}$ \\
\hline Regression equation: $\operatorname{Pr}=0.03+0.015$ & $+0 \cdot 1241$ & $14 \mathrm{~m}+0 \cdot 0 \ln ($ & $=0.006)$ & & & \\
\hline
\end{tabular}


different examiners. A more objective test of pupillary reactivity such as IRP may therefore be more reliable and useful than the clinical test.

To our knowledge, IRP has not been used previously to investigate CRVO. Previous studies using IRP have demonstrated that pupillary reactions in other conditions such as diabetes mellitus ${ }^{1314}$ and Parkinson's disease ${ }^{18}$ are abnormal in both eyes of patients, by comparing their IRP parameters with those of young normal controls. In such normal subjects the dilated pupillary diameter has been measured as between $4.7^{18}$ and $6.7 \mathrm{~mm},{ }^{14}$ the constricted pupillary diameter has been measured as between $3 \cdot 1^{14}$ and $2.5 \mathrm{~mm},{ }^{18}$ and therefore the $\mathrm{D} / \mathrm{C}$ ratio has varied between 1.9 and $2 \cdot 2$. Reported values for the other IRP parameters in these controls are $240 \pm 18 \mathrm{~ms}$ for latency and $4.9 \pm 1 \mathrm{~mm} / \mathrm{s}$ for rate. ${ }^{18}$

Previous studies have also shown uniocular abnormalities in the affected eyes of patients with optic neuritis. ${ }^{15-17}$ In our study, IRP parameters have been shown to be significantly affected in eyes with CRVO by using the patients' own unaffected eye as a control. The lack of age matched controls makes it inadvisable to compare our results with those of normal subjects. The differences in IRP parameters between affected and unaffected eyes of patients with rubeosis were all significantly greater than in those without rubeosis. IRP has also shown differences in the absolute values of some individual parameters, between the affected eyes of patients with rubeosis and those without. However, these differences did not achieve statistical significance, possibly because the number of patients was too small.

Ranking of the individual IRP parameters, and of the interocular differences, showed a trend whereby the results of rubeotic patients were in general and most abnormal. However, individual variability was such that no single parameter was reliable in the prediction of rubeosis.

Using discriminant analysis on a combination of both eyes' primary IRP parameters, IRP statistically significantly identified those patients who developed rubeosis with $83 \%$ sensitivity and $95 \%$ specificity. These figures represent an improvement in specificity over any neutral density filter threshold in our hands, an improvement in sensitivity over the RAPD cut-off level of $\geq 0.9 \mathrm{LU}$, and the same sensitivity as the RAPD level of $\geq 0.6 \mathrm{LU}$. Discriminant analysis of the IRP data may be accurate in prediction because the combination of all eight parameters generates an index that is not very susceptible to variations in single parameters. In addition, IRP parameters are continuous variables that can be measured accurately, as opposed to the RAPD which is a relatively 'blunt' measurement of a discontinuous variable, the minimum value of which is 0 . This makes analysis of the results of IRP more flexible; no amount of data analysis can differentiate patients with an RAPD of 0 who develop rubeosis from those with or without a measurable RAPD who do not develop rubeosis.

Both sensitivity and specificity levels would be changed by altering the $50 \%$ probability level used by discriminant analysis in the prediction of rubeosis. If it were deemed important either more definitely to exclude rubeosis or more definitely to predict it, the level of probability used by discriminant analysis in prediction could be raised or lowered accordingly.

We have demonstrated significant anisocoria in patients with CRVO both in the light and in the dark, although it is unclear why affected pupils should be larger than their unaffected fellows. It has been stated that 'with anisocoria . . . the defect is located in the efferent pathway. ${ }^{24}$ However, we have failed to show any efferent pupillary defect in CRVO; that there were no differences between direct and consensual pupillary reactions on stimulation of either affected or unaffected eyes, shows that the damage in CRVO must be in the afferent, not the efferent, limb of the pupil reflex arc.

Our results cannot therefore be explained by the physical presence of clinical (or subclinical) rubeosis interfering with pupillary movements, and, in any case we have shown differences in IRP parameters between affected and unaffected eyes both in patients with and without rubeosis. The damage to the pupil reflex arc in CRV.O may be due to ischaemic neuron loss within the retina, the extent of which is probably related to the degree of retinal ischaemia. This would explain why pupillary reactions are affected in CRVO, in proportion to the degree of ischaemia.

Both clinical and infrared pupillometry have merits and disadvantages. Both methods fail to identify a certain proportion of patients who develop rubeosis and wrongly identify some who do not, though IRP is more accurate. The neutral density filter test is widely available and has been shown to be reliable in experienced hands, but may be subject to interobserver differences that make it difficult to define absolute levels of abnormality. IRP is objective, repeatable, and generates much useful data, but the equipment required is sophisticated and expensive. However, even in its present early state of development, IRP may be superior to clinical testing, and the increasing use and availability of information technology make IRP more suitable to further research and evaluation.

Using the statistical model built with the data from this study it would be possible to investigate the accuracy of prospective prediction of rubeosis from IRP data in new cases of CRVO. Such a prediction may be of use in deciding how closely to follow up patients with CRVO and whether or not to treat them with panretinal photocoagulation to reduce the incidence of rubeosis. A further prospective study would be necessary to evaluate this.

The authors wish gratefully to acknowledge the help and financia assistance of the Special Trustees of Bristol Eye Hospital to thank Mr J C Dean Hart for reading the manuscript, Mr A Hughes of Bristol University Department for advice about statistics, and the help of Mr W Ayliffe in drafting the original grant application.

1 Laatikainen L. Preliminary report of retinal panphotocoagulation on rubeosis iridis and neovascular glaucoma. Brf Ophthalmol 1977; 61: 278-84

2 Margaral LE, Brown GC, Augsburger JJ, Donoso LA Efficacy of panretinal photocoagulation in preventing neovascular glaucoma following central retinal vein occlusion. Ophthalmology 1982; 89: 780-4.

3 Laatikainen L. A prospective follow-up study of panretina photocoagulation in preventing neovascular glaucoma folphotocoagulation in preventing neovascular glaucoma following ischaemic central retinal vein occ

4 Sanborn GE, Margaral LE, Jaeger EA. Venous occlusive 
disease of the retina. In: Tasman W, Jaeger EA, eds. Duane's clinical ophthalmology. Philadelphia: Lippincott, 1989: vol 3; Chapter 15, 11 .

5 Thompson HS, Montague P, Cox TA, Corbett JJ. The relationship between visual acuity, pupillary defect and relationship between visual acuity, pupillary
visual loss. Am f Ophthalmol 1982; 93: 681-8.

6 Servais GE, Thompson HS, Hayreh SS. Relative afferent pupillary defect in central retinal vein occlusion. Ophthalmology 1986; 93: 301-3.

7 Kaye SB, Harding SP. Early electroretinography in unilateral central vein occlusion as a predictor of rubeosis iridis. Arch Ophthalmol 1988; 106: 353-6.

8 Breton ME, Quinn GE, Keene S, Dahmen JC, Brucker AJ. Electroretinogram parameters at presentation as predictors of rubeosis in central retinal vein occlusion patients. Ophthalmology 1989; 96: 1343-52.

9 Hayreh SS, Klugman MR, Podhajsky P, Kolder HE. Electroretinography in central retinal vein occlusion: correlation of electroretinographic findings with pupillary relation of electroretinographic findings with pupillary
abnormalities. Graefes Arch Clin Exp Ophthalmol 1989; 227: 549-61.

10 Grey RHB, Bloom PA. Retinal ischaemia and relative afferent pupil defects in central retinal vein occlusion. Eurf Ophthalmol 1991

11 Morrell AJ, Thompson DA, Gibson JM, Kritzinger EE, Drasdo N. Electroretinography as a prognostic factor of neovascularization in CRVO. Eye 1991; 5: 362-8.

12 Papakostopoulos D, Bloom PA, Grey RHB, Dean Hart JC. The electro-oculogram in central retinal vein occlusion. BrF Ophthalmol 1992; 76: 515-9.
13 Smith SA, Smith SE. Reduced pupillary light reflexes in diabetic autonomic neuropathy. Diabetologica 1983; 24: 230-2.

14 Papakostopoulos D, Dean Hart JC, Corrall R. Comparison of pupillometry, electroretinography, and pattern visual evoked potentials in diabetics with and without retinopathy. evoked potentials in diabetics with

15 Ellis CJK. The afferent pupillary defect in acute optic neuritis. I Neurol Neurosurg Psychiatry 1979; 42: 1008-17.

16 Alexandridis E, Argyropoulos T, Krastel H. The latent period of the pupil light reflex in lesions of the optic nerve. Ophthalmologica 1981; 182: $211-7$.

17 Cex TA. Pupillography of a relative afferent pupillary defect. Am ₹ Ophthalmol 1986; 101: $320-4$

18 Harris JP. The pupil in Parkinson's disease. F Psychophysiol 1991; 5: 251-4.

19 Thompson HS, Corbett JJ, Cox TA. How to measure the relative afferẻnt pupil defect. Surv Ophthalmol 1981; 26: 39-42.

20 Leenderz JA. In: Alexandridis E, Leenderz JA, Barbur JL. Methods for studying the behaviour of the pupil. $\mathcal{F}$ Psycho-

21 Armitage P, Berry G. Statistical methods in medical practice, 2nd ed. Oxford: Blackwell, 1987

22 Fluzy B, Riedwyl H. Multivariate statistics - a practical approach. London: Chapman and Hall, 1988.

23 Hayreh SS. Classification of central retinal vein occlusion. Ophthalmology 1983; 90: 458-74.

24 Alexandridis E. Recent advances in the evaluation of afferent pupillary defects. F Psychophysiol 1991; 5: 241-7. 